\title{
The Impacts of Domestication and Agricultural Practices on Legume Nutrient Acquisition Through Symbiosis With Rhizobia and Arbuscular Mycorrhizal Fungi
}

\author{
Ailin Liu*t, Yee-Shan Kut, Carolina A. Contador ${ }^{\dagger}$ and Hon-Ming Lam* \\ Centre for Soybean Research of the State Key Laboratory of Agrobiotechnology and School of Life Sciences, The Chinese \\ University of Hong Kong, Hong Kong, China
}

\section{OPEN ACCESS}

Edited by:

Gaofeng Zhou,

Department of Primary Industries

and Regional Development

of Western Australia, Australia

Reviewed by:

Camilla Fagorzi,

University of Florence, Italy

Alexandra Stoll,

Universidad Católica del Norte, Chile

*Correspondence:

Ailin Liu

merestarry@gmail.com

Hon-Ming Lam

honming@cuhk.edu.hk

${ }^{\dagger}$ These authors have contributed equally to this work

Specialty section:

This article was submitted to Evolutionary and Population Genetics,

a section of the journal

Frontiers in Genetics

Received: 16 July 2020 Accepted: 08 September 2020 Published: 30 September 2020

Citation:

Liu A, Ku Y-S, Contador CA and Lam H-M (2020) The Impacts

of Domestication and Agricultural

Practices on Legume Nutrient Acquisition Through Symbiosis With

Rhizobia and Arbuscular Mycorrhizal

Fungi. Front. Genet. 11:583954.

doi: 10.3389/fgene.2020.583954
Legumes are unique among plants as they can obtain nitrogen through symbiosis with nitrogen-fixing rhizobia that form root nodules in the host plants. Therefore they are valuable crops for sustainable agriculture. Increasing nitrogen fixation efficiency is not only important for achieving better plant growth and yield, but it is also crucial for reducing the use of nitrogen fertilizer. Arbuscular mycorrhizal fungi (AMF) are another group of important beneficial microorganisms that form symbiotic relationships with legumes. AMF can promote host plant growth by providing mineral nutrients and improving the soil ecosystem. The trilateral legume-rhizobia-AMF symbiotic relationships also enhance plant development and tolerance against biotic and abiotic stresses. It is known that domestication and agricultural activities have led to the reduced genetic diversity of cultivated germplasms and higher sensitivity to nutrient deficiencies in crop plants, but how domestication has impacted the capability of legumes to establish beneficial associations with rhizospheric microbes (including rhizobia and fungi) is not well-studied. In this review, we will discuss the impacts of domestication and agricultural practices on the interactions between legumes and soil microbes, focusing on the effects on AMF and rhizobial symbioses and hence nutrient acquisition by host legumes. In addition, we will summarize the genes involved in legume-microbe interactions and studies that have contributed to a better understanding of legume symbiotic associations using metabolic modeling.

Keywords: legume-microbe interaction, arbuscular mycorrhizal fungi, symbiotic nitrogen fixation, rhizobia, domestication, metabolic modeling, metabolic profiling

\section{INTRODUCTION}

Major macronutrients such as nitrogen $(\mathrm{N})$, phosphorus $(\mathrm{P})$, and potassium $(\mathrm{K})$ play important roles in crop development. Lack of soil fertility is a vital constraint on crop production. To avoid intensifying the use of chemical fertilizers which may cause irreversible environmental damages including soil salinization and eutrophication of local lakes and rivers from fertilizer runoffs, plant growth-promoting rhizobacteria (PGPR) are regarded as efficient biofertilizers (Singh et al., 2016). 
The application of biofertilizers to the soil increases the biodiversity in the soil, and improves soil fertility through $\mathrm{N}_{2}$ fixation, as well as $\mathrm{P}$ and $\mathrm{K}$ mobilization in the form of organic acids (Egamberdiyeva and Höflich, 2004; Sulieman and Tran, 2014; Itelima et al., 2018).

Legumes are important crops in agriculture, not only because they are a protein-rich food source, but also because of their contribution to soil fertilization through symbiotic nitrogen fixation (SNF) as a result of their association with nitrogenfixing PGPR, i.e., rhizobia (Zahran, 1999). Each year, legumes can provide more than 70 million tonnes of $\mathrm{N}$ to soil (Brockwell et al., 1995). The symbiosis between legume and rhizobium is responsible for a substantial part of global $\mathrm{N}$ flux in which atmospheric $\mathrm{N}_{2}$ is fixed to form ammonia, nitrate, and organic nitrogen. Rhizobial species (including the genera of Mesorhizobium, Bradyrhizobium, Azorhizobium, Allorhizobium, and Sinorhizobium) infect legume roots and induce the formation of root nodules (Stacey, 2007; Gopalakrishnan et al., 2015). The infection is initiated by the flavonoids released by legume hosts that induce the expressions of nodulation (nod) genes in rhizobia, which in turn trigger root cell divisions by producing lipo-chitooligosaccharide (LCO) signals (Dakora, 1995, 2003). Nodules can generally be classified into determinate and indeterminate ones. Determinate nodules are round shaped, with a well-defined homogeneous central fixation zone containing infected rhizobia-filled cells surrounded by uninfected cells (Schultze and Kondorosi, 1998). Indeterminate nodules have a gradient of developmental stages from the nodule tip to the root as a result of a persistent meristem that generates new cells continuously (Crespi and Gálvez, 2000), which is absent in determinate nodules. Well-studied model species with indeterminate nodules include Medicago truncatula (barrelclover), Medicago sativa (alfalfa), and Pisum sativum (pea), while Glycine max (soybean), Vicia faba (fava bean), and Lotus japonicus (birdsfoot trefoil) are typical model species for the study of determinate nodules (Gage, 2004).

Besides rhizobia, legumes form symbiosis with soil fungi such as arbuscular mycorrhizal fungi (AMF) and Trichoderma spp. (TR). The symbioses with AMF and TR are considered to be beneficial for plant growth (Brundrett, 1991; Woo et al., 2014). AMF colonize plant roots and radiate their hyphae into the surrounding soil, complementing the host's root functions (Jansa et al., 2011). The enhanced root performance due to AMF has been shown in G. max (Wang et al., 2011), V. faba (Jia et al., 2004), M. sativa (Jansa et al., 2011), and Phaseolus vulgaris (common bean) (Tajini et al., 2012). Moreover, nodules normally have a high demand for inorganic phosphate (Pi) as nitrogenase functions in the bacteroid are highly ATP-consuming (Jakobsen, 1985; Liu et al., 2018). In such cases, AMF have the capability to accelerate the $\mathrm{Pi}$ uptake. The amount of $\mathrm{Pi}$ delivered to the plant varies with specific AMF (Ianson and Linderman, 1993; Valdenegro et al., 2001). On the other hand, TR-based biofertilizers have also been reported to enhance N, $\mathrm{P}$, and $\mathrm{K}$ uptakes (Amaresan et al., 2020). TR communicates with the plant root by chemical signals such as auxins and small peptides. They could also colonize plant roots by penetrating the outer layers of the root tissue. One of the well-known beneficial effects of TR to plants is the solubilization of Pi by acidification, chelation or redox activities to improve the Pi availability to the plant. The benefits of AMF and TR to crop growth have been comprehensively reviewed (Szczałba et al., 2019).

Domestication is the conversion of wild plant species to cultivated ones through human selection and breeding of desirable characteristics over many generations, but it often results in the loss of genetic diversity (Gepts, 2010). It is welldocumented that the domestication of legumes has emphasized the selection of favorable aboveground traits including larger seed size, palatability, reduced seed dormancy and heritability of other desirable agronomic traits (Abbo et al., 2014; Pérez-Jaramillo et al., 2016). Such a process of artificial selection has reduced the self-sustaining capability and increased sensitivities to diseases, abiotic stresses and nutrient depletion in cultivated legumes. Furthermore, artificial selection has also influenced underground traits including root architecture and root exudate composition, often unintentionally (Pérez-Jaramillo et al., 2016). This may affect the establishment of rhizospheric microbial communities in the soil where the legumes are grown. In this review, we will discuss how domestication and agricultural practices have influenced the interactions between legumes and rhizospheric microbes (rhizobia and fungi), with a focus on the potential impacts of such altered interactions on macronutrient acquisition by the host plant. We will also summarize the identified genes that regulate plant-rhizobia interactions in both plants and rhizobia, and the new study approaches using metabolic modeling and metabolic profiling, with the aim of contributing to a better understanding of legume-microbe symbiotic associations.

\section{DOMESTICATION AND AGRICULTURAL PRACTICES INFLUENCE THE DIVERSITY OF RHIZOBIA AND SOIL FUNGI}

Legume-rhizobium mutualism contributes to the vast majority of non-anthropogenically fixed $\mathrm{N}$ in terrestrial ecosystems (Cleveland et al., 1999), and it is especially susceptible to anthropogenic environmental changes (Kiers et al., 2002). Through mutualistic symbiosis, legumes receive ammonia fixed from atmospheric $\mathrm{N}_{2}$ by rhizobia in the root nodule, in exchange for providing rhizobia with a carbon source obtained through photosynthesis (Figure 1). The efficiency and intensity of SNF is dependent on both rhizobia and plant hosts under a specific set of conditions (Lau et al., 2012). A study comparing the SNF efficiencies between wild (local) varieties and cultivars in major legume crops showed that the wild populations of alfalfa, pea and feugreek (Trigonella foenumgraecum L.) had better performance than their cultivated counterparts (Provorov and Tikhonovich, 2003). On the other hand, a study using wild and cultivated soybeans inoculated with the slow-growing Bradyrhizobium japonicum strain USDA110 or the fast-growing Sinorhizobium fredii strain CCBAU45436, indicated the SNF efficiency was improved by the domestication process (Muñoz et al., 2016). Moreover, the activity and diversity of rhizobia can be affected by human activities including the use of $\mathrm{N}$ fertilizer, cropping system and soil management system (Ferreira et al., 2000; 


\section{Legume-AMF-rhizobia symbiosis}

- Alleviate nutrient deficiency

- Promote plant development

- Accelerate phosphorus uptake

- Enhance nitrogen fixation ability

\section{AMF symbiosis}

- Promote plant development

- Increase plant biotic and abiotic tolerance

- Enhance root nutrient uptake

- Transfer nutrients between plant and AMF (carbon, nitrogen and phosphorus).

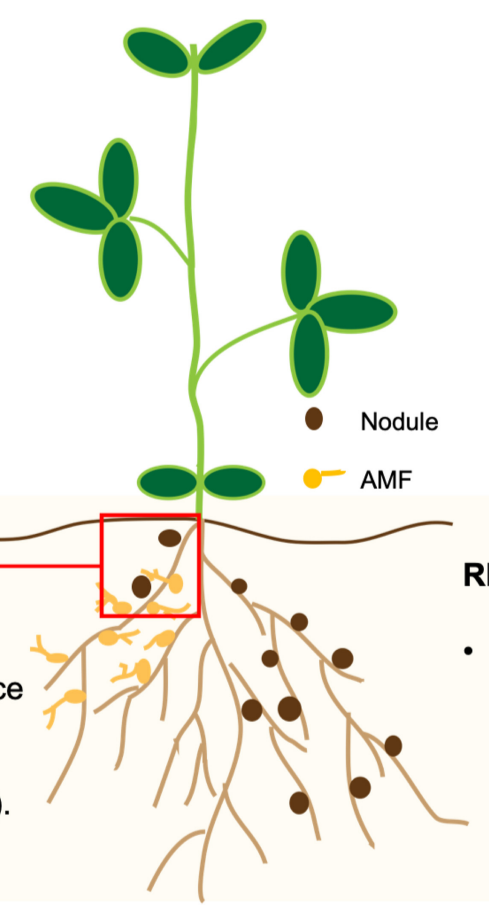

Rhizobia symbiosis

- Exchange fixed nitrogen for carbon source from plant by infecting roots and forming nodules.

FIGURE 1 | A schematic drawing representing the impacts of symbioses with arbuscular mycorrhizal fungi (AMF) and rhizobia on plant growth and nutrient uptake.

Bizarro et al., 2011). The utilization of high levels of $\mathrm{N}$ fertilizer across soil ecosystems may result in the breakdown of nitrogenfixing symbiosis between legumes and rhizobia (Foley et al., 2005). It was suggested that when the resources exchanged in mutualistic symbiosis are abundant in the soil and the host is less reliant on the microsymbiont, the plant-microbe interaction could shift from mutualism to parasitism (Bronstein, 2001). The genetic diversity of rhizobium in nodules of $P$. vulgaris was decreased partially due to the $\mathrm{N}$ fertilization (Caballero-Mellado and Martinez-Romero, 1999). A study showed that Trifolium species inoculated with long-term $\mathrm{N}$ fertilizer-treated rhizobial strains had less biomass and chlorophyll contents than plants inoculated with non-fertilizer treated rhizobia, implying an elevated $\mathrm{N}$ supply resulted in the evolution of less-mutualistic rhizobia that provide fewer growth benefits to plant hosts in the Trifolium-rhizobium symbiosis (Weese et al., 2015).

Arbuscular mycorrhizal fungi belong to the subphylum Glomeromycotina, which are asexual obligate biotrophs that infect roots and establish a mutualistic relationship with the host plant to complete their life cycle. The mutualism is characterized by the transfer of nutrients including $\mathrm{P}, \mathrm{N}$, and carbon (C) between the fungi and the plants (Figure 1). Moreover, AMF play an important role in improving $\mathrm{N}_{2}$ fixation by providing a favorable environment to facilitate the infection of plant roots by rhizobia (Mohammadi et al., 2012). It is believed that the responsiveness of crops to AMF is not under intentional selection by breeders during domestication (Bennett et al., 2013). However, agricultural activities such as soil disturbance, grazing, fertilizer application and monocropping may have reduced the AMF diversity and their community structure in the soil (Jansa et al., 2006). Plants having sufficient $\mathrm{P}$ supplies are also less responsive to AMF for symbiosis (Jansa et al., 2006). Moreover, soil types can also influence the structure of soil fungal communities (Chang et al., 2020). By simulating the monocropping of cultivated and wild soybeans in the greenhouse, it was shown that monocropping resulted in a stable fungal community in the rhizospheres of both types of soybeans, but with different community structures (Tian et al., 2020). Therefore, modern agricultural practices may have resulted in the reduced AMF diversity and the inadvertent selection of crop genotypes with reduced responsiveness to AMF for symbiosis (Bennett et al., 2013).

\section{WILD LEGUMES RECRUIT MORE DIVERSE RHIZOBIA AND SOIL FUNGI}

It is documented that domesticated legumes tend to have fewer compatible symbionts than wild legumes (Mutch and Young, 2004). Rhizobia varies on their ability to nodulate various legume species. Some strains show high nodulation specificities and only form nodules with a limited number of legume species, while others can have a wide range of hosts (Pueppke and Broughton, 1999). G. max is one of the most important cultivated legumes. G. soja is the wild progenitor species of $G$. max, with high genetic diversity and better resistance to environmental stresses (Muñoz et al., 2017). Both G. soja and G. $\max$ can be nodulated with rhizobia, including Sinorhizobium fredii, Bradyrhizobium japonicum and 
Bradyrhizobium elkanii (Wang et al., 2009). A study on bacterial isolates from G. soja nodules collected from different ecoregions in China showed that the biodiversity of rhizobia is associated with the geographical distribution of the particular ecotype of G. soja (Wu et al., 2011). Moreover, by comparing the rhizospheric bacteria between wild and cultivated soybeans in different soil types, wild soybean has the ability to recruit a higher abundance of Bradyrhizobium strains than cultivated soybean (Chang et al., 2019). A study of the impacts of domestication on the chickpea-Mesorhizobium symbiosis using 10 accessions of chickpea showed that the wild chickpea progenitor (Cicer reticulatum) could associate with more diverse Mesorhizobium populations than the cultivated chickpea (C. arietinum) (Kim et al., 2014).

By comparing the rhizospheric fungal communities of wild soybeans, ZYQ95 and 01-289, to those of cultivated soybeans, Williams 82 and Zhonghuang, the wild and cultivated germplasms were found to recruit different fungi in the rhizosphere (Chang et al., 2020). The wild soybeans recruited soil fungi with diverse potential functions while the cultivated soybeans mainly recruited those soil fungi which can enhance nutrient uptake by the plant (Chang et al., 2020). In another study conducted in the greenhouse, it was found that the genus Paraglomus was more enriched in the rhizosphere of wild soybean ZYQ95 while Funneliformis and Rhisophagus were more enriched in the rhizosphere of cultivated soybean Williams 82 (Zhang et al., 2019). In the field, no AMF could be found in the rhizosphere of Williams 82 while only Paraglomus was found in the rhizosphere of ZYQ95 under drought condition (Zhang et al., 2019). The reduced diversity of symbiotic rhizobia and fungi in modern legume cultivars compared to the wild relatives is likely a result of domestication. Agricultural practices such as monocropping might have played a role. Moreover, domesticated crops are usually grown in a confined cultivation area. As a result, the selection force on legumeassociated soil microbe diversity in complex natural habitats might be absent.

\section{AMF IMPROVE THE EFFICIENCY OF RHIZOBIUM-MEDIATED NITROGEN ASSIMILATION IN BOTH WILD AND DOMESTICATED LEGUMES}

In a survey of 27 crops including legumes such as chickpea, soybean, grass pea, lentil, white clover and common bean, the domesticated crops and their wild relatives were inoculated with Rhizophagus irregularis (Blaszk, Wubet, Renker \& Buscot) C. Walker \& A. Schüßler strain EEZ 58 (Gi), which is a common strain of AMF in wild and agricultural lands. The inoculation led to increases in leaf $\mathrm{Pi}$ concentrations across all domesticated crops and wild relatives tested (MartínRobles et al., 2018). In the same study, for the 14 nonleguminous crops such as barley, corn and tomato, when $\mathrm{Pi}$ availability in the soil was high, the growth benefits to the domesticated crops by the arbuscular mycorrhizae were reduced but not for their wild relatives (Martín-Robles et al., 2018). In another study, wild soybean (G. soja) or cultivated soybean (G. max) was inoculated with both Scutellospora heterogama (S. heterogama) and their own rhizobial cells (Eom et al., 1994). It was found that $S$. heterogama stimulated the triple symbiosis among the wild soybean plant, $S$. heterogama and the rhizobial cells (Eom et al., 1994; Figure 1). Furthermore, it was demonstrated that unimproved soybean accessions showed a greater mycorrhizal dependency (MD) than improved accessions (Khalil et al., 1994). When inoculated with the vascular-arbuscular mycorrhizal fungi, Gigaspora margarita or Glomus intraradices, under low soil $\mathrm{Pi}$ condition, the positive growth effects due to the inoculation were greater in the unimproved accessions than in the improved ones (Khalil et al., 1994). A follow-up study showed that the unimproved soybean accession having a high MD value, G. soja Sieb. \& Zucc. PI 468916, developed symbiosis with G. margarita more quickly than G. max (L.) Merr. cv. Mandarin (unimproved) and G. max cv. Swift (improved), which have intermediate and low MD values, respectively (Khalil et al., 1999). Among the three soybean accessions, G. soja Sieb. \& Zucc. PI 468916 also had higher phosphatase activities and higher percentage increases in phosphatase activities when inoculated with G. margarita (Khalil et al., 1999). In contrast, in a study on cowpea using three cultivated accessions, Katumani 80, KenKunde 1 and Kunde Mboga, and one wild accession, SP 219, it was found that the ability to respond to mycorrhizal inoculation was retained in the cultivated accessions, which are the common modern cultivars grown by smallholding farmers in Kenya (Oruru et al., 2017). In these experiments, the cowpea accessions were grown in sterilized soil inoculated with a filtrate from non-sterilized soil and a commercial mycorrhizal inoculum comprising Funneliformis mosseae, Glomus aggregatum, Glomus etunicatum, and Rhizophagus irregularis (Oruru et al., 2017). AMF root colonization was observed in all the accessions in both nonsterilized and sterilized soil. In all the accessions, the inoculation of the mycorrhizal inoculum improved the nodule number, dry weights of nodules, roots and shoots, and both the nitrogen and $\mathrm{Pi}$ levels in the shoots of all the wild and cultivated accessions. However, the increase in biomass of nodules, roots and shoots were more significant in the cultivated accessions than in the wild counterpart (Oruru et al., 2017). Katumani 80 and Kunde Mboga also had higher percentages of mycorrhizal colonization compared to the wild accession while Katumani 80 and KenKunde 1 had more nodules than the wild SP 219 (Oruru et al., 2017).

Although several studies showed that wild legumes benefited more from the inoculation with AMF than cultivated counterparts (Eom et al., 1994; Khalil et al., 1994, 1999; MartínRobles et al., 2018), the opposite effect of AMF was also reported (Oruru et al., 2017). It is important to note that different legumes and AMF species were tested in these studies. It has been pointed out that the responses to soil fungi could be genotype-specific, instead of wild versus cultivated accessions of the legume in question (Prashar and Vandenberg, 2017). As discussed above, the response to soil fungi is probably not intentionally selected 
for during domestication. Therefore, it may not be appropriate to generalize the observations to all wild and domesticated legumes.

\section{THE CAPABILITY TO RESPOND TO AMF AND Trichoderma spp. (TR) IS RETAINED IN MODERN LEGUME CULTIVARS}

During plant breeding, varieties which are more resistant to diseases are usually selected for. It has been hypothesized that such selections may also have influenced the susceptibility of these varieties to beneficial microbes such as AMF. When different varieties of chickpea were grown in paddock soil containing naturally occurring AMF, there was a correlation between the level of resistance to Phytophthora root rot (PRR) and the degree of AMF colonization on the root (Plett et al., 2016), where the PRR-susceptible variety, Sonali, had a significantly higher root AMF colonization level than the PRRresistant varieties, Yorker and PBA HatTrick, although such a correlation was absent when the varieties were grown in sterilized soil inoculated with Funneliformis mosseae (Plett et al., 2016). A possible explanation for such a phenomenon is that there is a certain degree of overlap between genes which confer resistance against beneficial AMF and those against pathogenic microbes (Plett et al., 2016). Although there are few studies on the response of wild legumes to TR, current findings also suggest that the capability to respond to TR is retained in domesticated legumes. In a study on 23 wild and cultivated lentil accessions inoculated with commercial TR inocula, RootShield ${ }^{\circledR}$ (RS) and RootShield ${ }^{\circledR}$ Plus (RSP), based on Trichoderma harzianum T22 and Trichoderma virens G41, respectively, the wild accession, Lens tomentosus PI 572390, had enhancements in most of the tested agronomic traits such as root and shoot biomass (Prashar and Vandenberg, 2017). Positive effects on the cultivated accessions by such inoculations were also observed (Prashar and Vandenberg, 2017). However, in some accessions, be they cultivated or wild, the inoculation had no or negative effects on the same agronomic traits (Prashar and Vandenberg, 2017). This showed that the TR responses were genotype-specific rather than distinguished along the line of wild versus domesticated accessions (Prashar and Vandenberg, 2017).

It was hypothesized that new high-yield crops may be less responsive to AMF compared to their ancestors (Lehmann et al., 2012). However, a meta-analysis of the data on 320 different crops, including those in the families Poaceae, Fabaceae, Pedaliaceae, Asteraceae, and Cucurbitaceae, from 39 published studies suggested that the new crops have not lost the ability to respond to AMF compared to their ancestors (Lehmann et al., 2012). Wild and domesticated legume accessions usually have distinct root system architectures. For example, in a study on the quantitative trait locus (QTL) of root system architecture in soybean, a recombinant inbred (RI) population was produced by crossing a G. $\max$ parent, V71-370, with a G. soja parent, PI407162 (Prince et al., 2015). The domesticated parent G. max V71-370 had a larger root system than the wild parent. The resulting RI population displayed a transgressive segregation of the root traits, including taproot length and total root length, from the domesticated and wild parents (Prince et al., 2015). In another study on the QTL governing the root architecture of soybean, a cultivated parent, G. max Dunbar, and a wild parent, G. soja PI 326582A, were used to construct the RI population (Manavalan et al., 2015). The cultivated parent had longer tap root and more lateral roots than the wild parent (Manavalan et al., 2015). In common bean (P. vulgaris), it was found that the wild accessions, A1 and A2, have longer specific root lengths (root length: root dry weight) than the cultivated accessions, M1, M2, M3, M4, and M5, and a lower root density (root dry weight: root volume) than the cultivated M2 (Pérez-jaramillo et al., 2017). A link between domestication, specific root morphology and rhizobacterial community assembly was observed (Pérezjaramillo et al., 2017). It is therefore convenient to suggest that the different root architecture of wild and domesticated legumes may result in different responses to soil fungi. However, based on the published data on root architecture and mycorrhizal growth responses, a meta-analysis suggested that there is no strong correlation between the mycorrhizal growth response and root diameter, root hair length or root hair density (Maherali, 2014). It appears that the differential responses to AMF colonization by different genotypes/accessions are influenced by factors other than the physical attributes of the root system. Similar to the improved efficiency of rhizobium-mediated nitrogen assimilation by AMF which happens in both wild and cultivated legumes, the capability to respond to AMF and TR is also retained in modern legume cultivars. As the symbiosis with AMF and TR are beneficial for plant growth (Brundrett, 1991; Woo et al., 2014), the capability of legumes to interact with these beneficial soil fungi should be have been selected by breeders during domestication.

\section{FUNCTIONAL GENES INVOLVED IN LEGUME-RHIZOBIUM-AMF SYMBIOSIS}

Symbiosis with rhizobia and AMF play a key role in plant nutrient acquisition. The mechanisms of these interactions and the genes driving these processes have been investigated for decades. In these endeavors, mutant libraries have been highly valuable resources for the research on symbiotic nitrogen fixation in legumes. They have been used for the identification and functional analyses of essential SNF-related genes. Over the years, legume mutants have been produced using physical/chemical mutagenesis, insertional mutagenesis and targeted genome editing tools (Le Signor et al., 2009; Urnov et al., 2010; Cui et al., 2013), including zinc finger nucleases (ZFNs), transcription activator-like effector nucleases (TALENs) and CRISPR-Cas systems (Wang L. et al., 2017).

Genes and/or functions required for rhizobium and AMF symbiosis are summarized in Table 1 . In $L$. japonicus, the biological functions of leghemoglobins were validated using RNAi and the CRISPR/Cas9 system (Ott et al., 2005; Wang et al., 2016, 2019). Leghemoglobins are plant hemoglobins required to maintain a low-oxygen environment inside root nodules for the efficient functioning of nitrogenases in bacteroids (VázquezLimón et al., 2012). The Ljlb1, Ljlb2, and Ljlb3 mutants had 
TABLE 1 | Functional genes involved in legume symbiosis.

\begin{tabular}{|c|c|c|c|}
\hline Gene & Function & Organism & References \\
\hline LjLB1 & Leghemoglobin & Lotus japonicus & Ott et al., 2005; Wang et al., 2016, 2019 \\
\hline LjLB2 & Leghemoglobin & Lotus japonicus & Ott et al., 2005; Wang et al., 2016, 2019 \\
\hline LjLB3 & Leghemoglobin & Lotus japonicus & Ott et al., 2005; Wang et al., 2016, 2019 \\
\hline nifV & Homocitrate synthase & Azorhizobium caulinodans ORS571 and Bradyrhizobium & Nouwen et al., 2017 \\
\hline Fen1 & Homocitrate synthase & Lotus japonicus & Imaizumi-Anraku et al., 1997 \\
\hline Rj4 & Symbiotic partnership specificity & Glycine max & Hayashi et al., 2014; Tang et al., 2016 \\
\hline MtNFS1 & Symbiotic partnership specificity & Medicago truncatula Jemalong A17 & Wang Q. et al., 2017; Yang S. et al., 2017 \\
\hline MtNFS2 & Symbiotic partnership specificity & Medicago truncatula Jemalong A17 & Wang Q. et al., 2017; Yang S. et al., 2017 \\
\hline SYMRK & $\begin{array}{l}\text { Infection thread initiation and } \\
\text { nodule development by rhizobia }\end{array}$ & Lotus japonicus & Kistner et al., 2005 \\
\hline CASTOR & $\begin{array}{l}\text { Infection thread initiation and } \\
\text { nodule development by rhizobia }\end{array}$ & Lotus japonicus & Kistner et al., 2005 \\
\hline POLLUX & $\begin{array}{l}\text { Infection thread initiation and } \\
\text { nodule development by rhizobia }\end{array}$ & Lotus japonicus & Kistner et al., 2005 \\
\hline SYM3 & $\begin{array}{l}\text { Infection thread initiation and } \\
\text { nodule development by rhizobia }\end{array}$ & Lotus japonicus & Kistner et al., 2005 \\
\hline SYM6 & Infection thread initiation & Lotus japonicus & Kistner et al., 2005 \\
\hline SYM15 & $\begin{array}{l}\text { Infection thread initiation and } \\
\text { nodule development by rhizobia }\end{array}$ & Lotus japonicus & Kistner et al., 2005 \\
\hline \multirow[t]{4}{*}{ SYM24 } & $\begin{array}{l}\text { Infection thread initiation and } \\
\text { nodule development by rhizobia }\end{array}$ & Lotus japonicus & Kistner et al., 2005 \\
\hline & Leghemoglobin & Medicago truncatula & Liese et al., 2017 \\
\hline & Nicotianamine synthase-like protein & Medicago truncatula & Liese et al., 2017 \\
\hline & $\begin{array}{l}\text { Nodule-specific cysteine-rich } \\
\text { peptides }\end{array}$ & Medicago truncatula & Liese et al., 2017 \\
\hline GmEXLB1 & $\begin{array}{l}\text { Regulation of root development and } \\
\text { responses to abiotic stress }\end{array}$ & Glycine max & Kong et al., 2019 \\
\hline GmACP1 & Acid phosphatase & Glycine max & Zhang et al., 2014 \\
\hline
\end{tabular}

elevated free-oxygen concentrations in infected zones and $\mathrm{N}_{2}$ fixation was abolished (Ott et al., 2005; Wang et al., 2019). Transcript analyses of bacteroid genes from the nodules of these mutants revealed lower expression levels of nif and fix genes compared to those from the wild type (Ott et al., 2005, 2009). In particular, the NifH protein was not detected despite the presence of nifH transcripts in the mutant nodules (Ott et al., 2005).

Efficient nitrogenase activities also depend on other conditions besides the microaerobic environment (Kuzma et al., 1993). Homocitrate is a component of the ironmolybdenum cofactor of nitrogenases (Rubio and Ludden, 2008). For rhizobia lacking the homocitrate synthase-encoding gene (nifV), homocitrate supplied by the host plant is a key element of successful SNF, as demonstrated using an SNFdefective L. japonicus mutant, fen1 (Imaizumi-Anraku et al., 1997). A homocitrate synthase gene, FEN1, in the host plant was identified as responsible for compensating for the lack of nif $V$ in rhizobia (Hakoyama et al., 2009). Additionally, an external supply of homocitrate was shown to restore the nitrogen-fixing capacity in the ineffective nodules.

On the other hand, the editing of genes responsible for the recognition mechanism underlying legume-rhizobium specificity enables nodulation with unspecific strains. In soybean, the disruption of the dominant allele $R j 4$ allowed nodulation with some strains of Bradyrhizobium japonicum and Bradyrhizobium elkanii (Hayashi et al., 2014; Tang et al., 2016). Rj4 encodes a thaumatin-like protein that usually restricts nodulation with these ineffective rhizobial strains. In M. truncatula Jemalong A17, the editing of two nodule cysteine-rich (NCR) peptideencoding genes, MtNFS1 and MtNFS2, allowed nodulation by S. meliloti strain Rm41 (Wang Q. et al., 2017; Yang S. et al., 2017). NCR peptides control and regulate the symbiotic partnership specificity in M. truncatula. MtNFS1 and MtNFS2 were identified using a recombinant inbred line (RIL) population of Jemalong A17 and DZA315. Parental genotypes were segregated according to their ability to form functional nodules with $S$. meliloti strain Rm41 or not (Wang Q. et al., 2017; Yang S. et al., 2017).

Seven L. japonicus genes (SYMRK, CASTOR, POLLUX, SYM3, SYM6, SYM15, and SYM24) are required for infection thread initiation for both fungal and bacterial symbiosis (Kistner et al., 2005). Mutant phenotypes showed that these genes are involved in the intracellular infection by fungal and bacterial symbionts. Additionally, these genes are required for nodule development by rhizobia, specifically for the formation of nodule primordia, except SYM6, since small nodule-like structures could still be observed on sym6 mutants during the interaction with Mesorhizobium loti but not on the other six mutants. After inoculation with AMF, sym mutant roots had a limited ability to form arbuscules, indicating the key role of the symbiosisrelated genes for intracellular infection by fungal partners (Kistner et al., 2005). 
Symbiotic nitrogen fixation in nodules is also affected when the growth is slow due to nutrient deficiency. An RNASeq transcriptome profiling of the nodules of $M$. truncatula inoculated with $S$. meliloti under P-deficient conditions revealed lower nitrogenase activities (Liese et al., 2017). The reduction in SNF efficiency was due to a downregulation of genes encoding leghemoglobins, nicotianamine synthase-like proteins and NCR peptides. Also, low-Pi conditions reduced growth, nodule numbers and $\mathrm{P}$ concentrations in stem, root and nodule tissues compared to the control (Liese et al., 2017). However, the $\mathrm{P}$ concentration in nodules was relatively higher than in stem and root tissues. In soybean, GmEXLB1, encoding an expansin, was identified as a key gene involved in the response to lowP stress through transcription profiling (Kong et al., 2019). Expansins are involved in the regulation of root development and responses to abiotic stresses in plants (Cosgrove, 2015). It was observed that GmEXLB1 expression was induced in the lateral roots of soybean under $\mathrm{P}$ starvation conditions. The ectopic expression of GmEXLB1 in transgenic Arabidopsis promoted changes to the root architecture by increasing the number and length of lateral roots, thus improving $\mathrm{P}$ acquisition under low-P conditions (Kong et al., 2019). The acid phosphatase-encoding gene, GmACP1, has also been associated with $\mathrm{P}$ efficiency in soybean (Zhang et al., 2014). GmACP1 is located in the QTL, $q$ PE8, related to soybean P efficiency, on chromosome 8 . Transgenic soybean hairy roots overexpressing GmACP1 showed a 2.3-fold increase in acid phosphatase activity and increased the efficiency of $\mathrm{P}$ usage by $11.2-20.0 \%$ relative to the control (Zhang et al., 2014).

\section{METABOLIC MODELING AND METABOLIC PROFILING STUDIES ON LEGUME-RHIZOBIUM SYMBIOSIS}

Legume-rhizobium symbiosis involves biological nitrogen fixation as well as the exchange of nutrients. Transport systems and carbon-nitrogen metabolism are coordinated to provide nutrients for effective SNF. Each host plantrhizobium interaction is association-specific and determines the accumulation of carbon and energy storage metabolites inside the microsymbionts (Terpolilli et al., 2012). Metabolic modeling provides new insights into the metabolism in plant systems. An emerging approach to studying the process of SNF in legumes is constraint-based modeling, which relies on network topology and the integration of genomic and high-throughput data for analyzing the metabolic capabilities of organisms (Feist et al., 2009; Heirendt et al., 2019). Among the most frequently used frameworks is flux balance analysis using genome-scale models (Orth et al., 2010). This approach has been successfully used to study the process of SNF carried out in mature nodules by rhizobia. Metabolic network reconstructions have been reported for S. meliloti (Zhao et al., 2012; diCenzo et al., 2016, 2018), Bradyrhizobium diazoefficiens (Yang Y. et al., 2017), the symbiotic forms of Rhizobium etli (Resendis-Antonio et al., 2007, 2012), and Sinorhizobium fredii (Contador et al., 2020). These studies included the nutrient requirements for each $\mathrm{N}_{2}$-fixing relationship and performed preliminary analyses of SNF such as flux analyses of relevant biochemical pathways (e.g., the TCA cycle, the pentose phosphate pathway, and the production of cofactors for nitrogenase) and determination of the genes required for an efficient SNF through computational simulations. However, these analyses simplified the plant metabolism by only including inputs from the host plant to the microsymbiont metabolism during symbiosis.

Recently, the impact of wild and cultivated soybeans on nitrogen fixation was assessed in the $S$. fredii model (Contador et al., 2020). Transcriptome profiles of $S$. fredii in symbiotic conditions were used to capture the differential nitrogen-fixing capacity of $S$. fredii strain CCBAU45436 in symbiosis with G. max C08 and G. soja W05, respectively. The bacteroid model quantified and predicted a higher nitrogen fixation activity and $\mathrm{C} / \mathrm{N}$ ratio of $S$. fredii with the cultivated soybean than with the wild accession. This is consistent with previous experimental observations that this soybean cultivar (C08) outperformed the wild accession (W05) in a series of nitrogen fixationrelated traits including nodule number, total nitrogen and total ureide accumulation, and new QTLs for ureide content and nodule fresh weight have been identified using RIL populations (Muñoz et al., 2016). An examination of these QTLs revealed a very low diversity in some regions among cultivated soybeans. Domestication process was suggested as the responsible for the selection of these traits (Muñoz et al., 2016).

The representation of whole-rhizobium metabolic networks has been achieved for S. meliloti and B. diazoefficiens USDA110 (diCenzo et al., 2016; Yang Y. et al., 2017). These reconstructions were used to build context-specific models to characterize the metabolic capabilities of rhizobia in bulk soil, rhizosphere and nodule bacteroids. However, metabolic models have been published for only two legume species, G. max and M. truncatula, despite the significance of legumes to sustainable agriculture. A compartmentalized reconstruction for G. max was used to construct a multi-organ model to represent the reserve mobilization in the cotyledon and hypocotyl/root tissues (Moreira et al., 2019). This reconstruction can also be used to represent other tissues and conditions since the whole set of metabolic reactions in soybean were used to construct the metabolic model. Annotations of the G. max genome were used to define the gene-protein-reaction associations in the model. On the other hand, the M. truncatula model was used to capture both biomass production during day and night conditions and host-microsymbiont interactions (Pfau et al., 2018). This was the first attempt to elucidate the effects of symbiosis on metabolic fluxes and plant growth. Computational analyses revealed the costs and benefits of the symbiotic system for biomass growth when external ammonium is not available. Recently, the $M$. truncatula model was built to represent multi-organism metabolic interactions in different developmental zones within the nodule during nitrogen fixation (diCenzo et al., 2020). The multi-organism model consisted of $M$. truncatula nodulated by $S$. meliloti Rm1021. The plant system was represented by a multi-compartmental reconstruction that includes root and shoot tissues together with five nodule zones (apical meristem, distal, proximal, interzone, and nitrogen fixation zones). The 
accuracy of the metabolic reconstruction for S. meliloti was improved over the previous versions of the model. The integrated model was used to evaluate the use of nutrients by $\mathrm{N}_{2}$-fixing bacteroids, $\mathrm{N}_{2}$ fixation efficiency and costs related to the nitrogen fixation process.

The metabolic states of the legume-rhizobium association can also be assessed by performing metabolic profiling (Roessner et al., 2001; Rambla et al., 2015), which can provide a comprehensive picture of a particular sample or a genetically manipulated system. Metabolic profiling has been used to study metabolic shifts in SNF associations. Recently, metabolic profiling were performed on effective and ineffective nodules of soybean to identify the active processes according to the partners involved in the symbiosis (Agtuca et al., 2020). Metabolite levels were determined to characterize the different plant phenotypes and interactions with rhizobia. Similar comparative studies have been performed in Medicago and L. japonicus to investigate metabolites and related pathways that influence nodule metabolism during nitrogen fixation (Desbrosses et al., 2005; Ye et al., 2013; Gemperline et al., 2015). Other metabolomic studies have characterized the differentiation process from freeliving rhizobia into bacteroids to detect differences in the metabolite composition of these two physiological conditions (Vauclare et al., 2013). Metabolite profiling of root hairs was also performed to characterize the early stage of rhizobial infection, by identifying those metabolites the accumulation of which was regulated in response to rhizobial inoculation (Brechenmacher et al., 2010).

\section{CONCLUSION AND PERSPECTIVE}

Legumes engage in mutualistic relationships with rhizobia and mycorrhizal fungi, enabling them to obtain essential nutrients, promote growth, and enhance biotic and abiotic stress resistance. There is extensive evidence to support that AMF affect the establishment and functions of rhizobial nodulation in both wild and cultivated legumes and enhance nitrogen acquisition in the host plant through SNF. However, domestication has reduced the genetic diversity in host plants and impacted their compatibility with rhizobial strains and AMF. And the intensive applications of chemical fertilizers and large-scale monoculture

\section{REFERENCES}

Abbo, S., Pinhasi van-Oss, R., Gopher, A., Saranga, Y., Ofner, I., and Peleg, Z. (2014). Plant domestication versus crop evolution: a conceptual framework for cereals and grain legumes. Trends Plant Sci. 19, 351-360. doi: 10.1016/j.tplants. 2013.12.002

Agtuca, B. J., Stopka, S. A., Evans, S., Samarah, L., Liu, Y., Xu, D., et al. (2020). Metabolomic profiling of wild-type and mutant soybean root nodules using laser-ablation electrospray ionization mass spectrometry reveals altered metabolism. Plant J. 103, 1937-1958. doi: 10.1111/tpj.14815

Amaresan, N., Senthilkumar, M., and Krishna Kumar, A. S. (2020). Microbial Mitigation of Stress Response of Food Legumes. Boca Raton, FL: CRC PRESS (Taylor \& Francis Group).

Bennett, A. E., Daniell, T. J., and White, P. J. (2013). "Benefits of breeding crops for yield response to soil organisms," in Molecular Microbial Ecology of the farming practices during domestication actually have a negative impact on AMF community structures and their colonization of legume roots. It is important for researchers to engineer or screen for rhizobium strains, which are both competent for nodulation and capable of high nitrogen fixation efficiency, and AMF, which can effectively improve the nutrient acquisition by the host plants. Meanwhile, it is also vital to improve host plant's ability to interact with the best beneficial mutualistic symbionts. Understanding the genetic control of the symbiosis specificity between wild and cultivated legumes and identifying the key genetic factors controlling the symbiotic interaction will provide useful information for improving legume-soil microbe symbiosis. Moreover, utilizing advanced approaches such as metabolic modeling and metabolic profiling to investigate the molecular mechanisms of metabolite exchanges among legumes, AMF and rhizobia under nutrient-deficient conditions will help researchers better understand legume-microbe symbiosis, and ultimately contribute to the implementation of sustainable agriculture.

\section{AUTHOR CONTRIBUTIONS}

$\mathrm{H}-\mathrm{ML}$ and AL planned and coordinated the writing and finished the final draft. AL and Y-SK put together the first complete draft. CC contributed to the literature search and writing. All authors contributed to the article and approved the submitted version.

\section{FUNDING}

This work was supported by the Hong Kong Research Grants Council Area of Excellence Scheme (AoE/M-403/16) and the Lo Kwee-Seong Biomedical Research Fund. Any opinions, findings, conclusions, or recommendations expressed in this publication do not reflect the views of the Government of the Hong Kong Special Administrative Region or the Innovation and Technology Commission.

\section{ACKNOWLEDGMENTS}

Jee-Yan Chu edited the manuscript.
Rhizosphere, ed. F. J. de Bruijn (Hoboken, NJ: John Wiley \& Sons, Inc), 17-27. doi: 10.1002/9781118297674.ch3

Bizarro, M. J., Giongo, A., Vargas, L. K., Roesch, L. F. W., Gano, K. A., de Sá, E. L. S., et al. (2011). Genetic variability of soybean Bradyrhizobia populations under different soil managements. Biol. Fertil. Soils 47, 357-362. doi: 10.1007/s00374010-0512-6

Brechenmacher, L., Lei, Z., Libault, M., Findley, S., Sugawara, M., Sadowsky, M. J., et al. (2010). Soybean metabolites regulated in root hairs in response to the symbiotic bacterium Bradyrhizobium japonicum. Plant Physiol. 153, 1808-1822. doi: $10.1104 /$ pp.110.157800

Brockwell, J., Bottomley, P. J., and Thies, J. E. (1995). "Manipulation of rhizobia microflora for improving legume productivity and soil fertility: a critical assessment," in Management of Biological Nitrogen Fixation for the Development of More Productive and Sustainable Agricultural Systems, eds J. K. Ladha and M. B. Peoples (Dordrecht: Springer), doi: 10.1007/978-94-011-0055-7_7 
Bronstein, J. L. (2001). The exploitation of mutualisms. Ecol. Lett. 4, 277-287. doi: 10.1046/j.1461-0248.2001.00218.x

Brundrett, M. (1991). Mycorrhizas in natural ecosystems. Adv. Ecol. Res. 21, 171-313. doi: 10.1016/S0065-2504(08)60099-9

Caballero-Mellado, J., and Martinez-Romero, E. (1999). Soil fertilization limits the genetic diversity of Rhizobium in bean nodules. Symbiosis 26, 111-121.

Chang, C., Chen, W., Luo, S., Ma, L., Li, X., and Tian, C. (2019). Rhizosphere microbiota assemblage associated with wild and cultivated soybeans grown in three types of soil suspensions. Arch. Agron. Soil Sci. 65, 74-87. doi: 10.1080/ 03650340.2018.1485147

Chang, C., Zhang, J., Liu, T., Song, K., Xie, J., Luo, S., et al. (2020). Rhizosphere fungal communities of wild and cultivated soybeans grown in three different soil suspensions. Appl. Soil Ecol. 153:103586. doi: 10.1016/j.apsoil.2020.103586

Cleveland, C. C., Townsend, A. R., Schimel, D. S., Fisher, H., Howarth, R. W., Hedin, L. O., et al. (1999). Global patterns of terrestrial biological nitrogen (N2) fixation in natural ecosystems. Global Biogeochem. Cycles 13, 623-645. doi: 10.1002/(ISSN)1944-9224

Contador, C. A., Lo, S.-K., Chan, S. H. J., and Lam, H.-M. (2020). Metabolic analyses of nitrogen fixation in the soybean microsymbiont Sinorhizobium fredii using constraint-based modeling. mSystems 5, e516-e519.

Cosgrove, D. J. (2015). Plant expansins: diversity and interactions with plant cell walls. Curr. Opin. Plant Biol. 25, 162-172. doi: 10.1016/j.pbi.2015.05.014

Crespi, M., and Gálvez, S. (2000). Molecular mechanisms in root nodule development. J. Plant Growth Regul. 19, 155-166. doi: 10.1007/s003440000023

Cui, Y., Barampuram, S., Stacey, M. G., Hancock, N., Findley, S., Mathieu, M., et al. (2013). Tntl retrotransposon mutagenesis: a tool for soybean functional genomics. Plant Physiol. 161, 36-37. doi: 10.1104/pp.112.205369

Dakora, F. D. (1995). Plant flavonoids: biological molecules for useful exploitation. Aust. J. Plant Physiol. 22, 87-99. doi: 10.1071/PP9950087

Dakora, F. D. (2003). Defining new roles for plant and rhizobial molecules in sole and mixed plant cultures involving symbiotic legumes. New Phytol. 158, 39-49. doi: 10.1046/j.1469-8137.2003.00725.x

Desbrosses, G. G., Kopka, J., and Udvardi, M. K. (2005). Lotus japonicus metabolic profiling. Development of gas chromatography-mass spectrometry resources for the study of plant-microbe interactions. Plant Physiol. 137, 1302-1318. doi: 10.1104/pp.104.054957

diCenzo, G. C., Benedict, A. B., Fondi, M., Walker, G. C., Finan, T. M., Mengoni, A., et al. (2018). Robustness encoded across essential and accessory replicons of the ecologically versatile bacterium Sinorhizobium meliloti. PLoS Genet. 14:e1007357. doi: 10.1371/journal.pgen.1007357

diCenzo, G. C., Checcucci, A., Bazzicalupo, M., Mengoni, A., Viti, C., Dziewit, L., et al. (2016). Metabolic modelling reveals the specialization of secondary replicons for niche adaptation in Sinorhizobium meliloti. Nat. Commun. 7, 1-10. doi: 10.1038/ncomms12219

diCenzo, G. C., Tesi, M., Pfau, T., Mengoni, A., and Fondi, M. (2020). Genomescale metabolic reconstruction of the symbiosis between a leguminous plant and a nitrogen-fixing bacterium. Nat. Commun. 11:2574.

Egamberdiyeva, D., and Höflich, G. (2004). Effect of plant growth-promoting bacteria on growth and nutrient uptake of cotton and pea in a semi-arid region of Uzbekistan. J. Arid Environ. 56, 293-301. doi: 10.1016/S0140-1963(03) 00050-8

Eom, A. H., Lee, S. S., Ahn, T. K., and Lee, M. W. (1994). Ecological roles of arbuscular mycorrhizal fungi in two wild legume plants. Mycoscience 35, 69-75. doi: $10.1007 / \mathrm{bf} 02268531$

Feist, A. M., Herrgård, M. J., Thiele, I., Reed, J. L., and Palsson, B. Ø (2009). Reconstruction of biochemical networks in microorganisms. Nat. Rev. Microbiol. 7, 129-143. doi: 10.1038/nrmicro1949

Ferreira, M. C., De, S., Andrade, D., Ligia, L. M., Takemura, S. M., and Hungria, M. (2000). Tillage method and crop rotation effects on the population sizes and diversity of bradyrhizobia nodulating soybean. Soil Biol. Biochem. 32, 627-637. doi: 10.1016/S0038-0717(99)00189-3

Foley, J. A., DeFries, R., Asner, G. P., Barford, C., Bonan, G., Carpenter, S. R., et al. (2005). Global consequences of land use. Science 309, 570-574. doi: 10.1126/ science. 1111772

Gage, D. J. (2004). Infection and invasion of roots by symbiotic, nitrogen-fixing rhizobia during nodulation of temperate legumes. Microbiol. Mol. Biol. Rev. 68, 280-300. doi: $10.1128 / \mathrm{mmbr} .68 .2 .280-300.2004$
Gemperline, E., Jayaraman, D., Maeda, J., Ané, J.-M., and Li, L. (2015). Multifaceted investigation of metabolites during nitrogen fixation in Medicagovia high resolution MALDI-MS Imaging and ESI-MS. J. Am. Soc. Mass Spectrom 26, 149-158. doi: 10.1007/s13361-014-1010-0

Gepts, P. (2010). "Crop domestication as a long-term selection experiment," in Plant Breeding Reviews, eds R. Singh and P. Jauhar (Oxford: John Wiley \& Sons, Inc), 1-44. doi: 10.1002/9780470650288.ch1

Gopalakrishnan, S., Sathya, A., Vijayabharathi, R., Varshney, R. K., Gowda, C. L. L., and Krishnamurthy, L. (2015). Plant growth promoting rhizobia: challenges and opportunities. 3 Biotech 5, 355-377. doi: 10.1007/s13205-014-0241-x

Hakoyama, T., Niimi, K., Watanabe, H., Tabata, R., Matsubara, J., Sato, S., et al. (2009). Host plant genome overcomes the lack of a bacterial gene for symbiotic nitrogen fixation. Nature 462, 514-517. doi: 10.1038/nature08594

Hayashi, M., Shiro, S., Kanamori, H., Mori-Hosokama, S., Sasaki-Yamagata, H., Sayama, T., et al. (2014). A thaumatin-like protein, Rj4, controls nodule symbiotic specificity in soybean. Plant Cell Physiol. 55, 1679-1689. doi: 10.1093/ pcp/pcu099

Heirendt, L., Arreckx, S., Pfau, T., Mendoza, S. N., Richelle, A., Heinken, A., et al. (2019). Creation and analysis of biochemical constraint-based models using the COBRA toolbox v.3.0. Nat. Protoc. 14, 639-702. doi: 10.1038/s41596-0180098-2

Ianson, D., and Linderman, R. (1993). Variation in the response of nodulating pigeonpea (Cajanus cajan) to different isolates of mycorrhizal fungi. Symbiosis $15,105-119$.

Imaizumi-Anraku, H., Kawaguchi, M., Koiwa, H., Akao, S., and Syôno, K. (1997). Two ineffective-nodulating mutants of Lotus japonicus-different phenotypes caused by the blockage of endocytotic bacterial release and nodule maturation. Plant Cell Physiol. 38, 871-881. doi: 10.1093/oxfordjournals.pcp.a029246

Itelima, J., Bang, W., Onyimba, I., Sila, M., and Egbere, O. (2018). Bio-fertilizers as key player in enhancing soil fertility and crop productivity: a review. J. Microbiol. Biotechnol. Rep. 1.

Jakobsen, I. (1985). The role of phosphorus in nitrogen fixation by young pea plants (Pisum sativum). Physiol. Plant. 64, 190-196. doi: 10.1111/j.1399-3054.1985. tb02334.x

Jansa, J., Finlay, R., Wallander, H., Smith, F. A., and Smith, S. E. (2011). Role of mycorrhizal symbioses in phosphorus cycling. Soil Biol. 26, 137-168. doi: 10.1007/978-3-642-15271-9_6

Jansa, J., Wiemken, A., and Frossard, E. (2006). "The effects of agricultural practices on arbuscular mycorrhizal fungi," in Function of Soils for Human Societies and the Environment, eds E. Frossard, W. E. H. Blum, and B. P. Warkentin (London: Geological Society), 89-115. doi: 10.1144/gsl.sp.2006.266.01.08

Jia, Y., Gray, V. M., and Straker, C. J. (2004). The influence of rhizobium and arbuscular mycorrhizal fungi on nitrogen and phosphorus accumulation by Vicia faba. Ann. Bot. 94, 251-258. doi: 10.1093/aob/mch135

Khalil, S., Loynachan, T. E., and Tabatabai, M. A. (1994). Mycorrhizal dependency and nutrient uptake by improved and unimproved corn and soybean cultivars. Agron. J. 86, 949-958. doi: 10.2134/agronj1994.00021962008600060005x

Khalil, S., Loynachan, T. E., and Tabatabai, M. A. (1999). Plant determinants of mycorrhizal dependency in soybean. Agron. J. 91, 135-141. doi: 10.2134/ agronj1999.00021962009100010021x

Kiers, E. T., West, S. A., and Denison, R. F. (2002). Mediating mutualisms: farm management practices and evolutionary changes in symbiont co-operation. J. Appl. Ecol. 39, 745-754. doi: 10.1046/j.1365-2664.2002.00755.x

Kim, D. H., Kaashyap, M., Rathore, A., Das, R. R., Parupalli, S., Upadhyaya, H. D., et al. (2014). Phylogenetic diversity of Mesorhizobium in chickpea. J. Biosci. 39, 513-517. doi: 10.1007/s12038-014-9429-9

Kistner, C., Winzer, T., Pitzschke, A., Mulder, L., Sato, S., Kaneko, T., et al. (2005). Seven Lotus japonicus genes required for transcriptional reprogramming of the root during fungal and bacterial symbiosis. Plant Cell 17, 2217-2229. doi: $10.1105 /$ tpc. 105.032714

Kong, Y., Wang, B., Du, H., Li, W., Li, X., and Zhang, C. (2019). GmEXLB1, a soybean expansin-like B gene, alters root architecture to improve phosphorus acquisition in Arabidopsis. Front. Plant Sci. 10:808. doi: 10.3389/fpls.2019. 00808

Kuzma, M. M., Hunt, S., and Layzell, D. B. (1993). Role of oxygen in the limitation and inhibition of nitrogenase activity and respiration rate in individual soybean nodules. Plant Physiol. 101, 161-169. doi: 10.1104/pp.101.1.161 
Lau, J. A., Bowling, E. J., Gentry, L. E., Glasser, P. A., Monarch, E. A., Olesen, W. M., et al. (2012). Direct and interactive effects of light and nutrients on the legume-rhizobia mutualism. Acta Oecol. 39, 80-86. doi: 10.1016/j.actao.2012. 01.004

Le Signor, C., Savois, V., Aubert, G., Verdier, J., Nicolas, M., Pagny, G., et al. (2009). Optimizing TILLING populations for reverse genetics in Medicago truncatula. Plant Biotechnol. J. 7, 430-441. doi: 10.1111/j.1467-7652.2009.00410.x

Lehmann, A., Barto, E. K., Powell, J. R., and Rillig, M. C. (2012). Mycorrhizal responsiveness trends in annual crop plants and their wild relatives - a metaanalysis on studies from 1981 to 2010. Plant Soil 355, 231-250. doi: 10.1007/ s11104-011-1095-1

Liese, R., Schulze, J., and Cabeza, R. A. (2017). Nitrate application or P deficiency induce a decline in Medicago truncatula N2-fixation by similar changes in the nodule transcriptome. Sci. Rep. 7:46264.

Liu, A., Contador, C. A., Fan, K., and Lam, H. M. (2018). Interaction and regulation of carbon, nitrogen, and phosphorus metabolisms in root nodules of legumes. Front. Plant Sci. 9:1860. doi: 10.3389/fpls.2018.01860

Maherali, H. (2014). Is there an association between root architecture and mycorrhizal growth response?? New Phytol. 204, 192-200. doi: 10.1111/nph. 12927

Manavalan, L. P., Prince, S. J., Musket, T. A., Chaky, J., Deshmukh, R., Vuong, T. D., et al. (2015). Identification of novel QTL governing root architectural traits in an interspecific soybean population. PLoS One 10:e0120490. doi: 10. 1371/journal.pone. 0120490

Martín-Robles, N., Lehmann, A., Seco, E., Aroca, R., Rillig, M. C., and Milla, R. (2018). Impacts of domestication on the arbuscular mycorrhizal symbiosis of 27 crop species. New Phytol. 218, 322-334. doi: 10.1111/nph.14962

Mohammadi, K., Sohrabi, Y., Heidari, G., Khalesro, S., and Majidi, M. (2012). Effective factors on biological nitrogen fixation. Afr. J. Agric. Res. 7, 1782-1788. doi: 10.5897/ajarx11.034

Moreira, T. B., Shaw, R., Luo, X., Ganguly, O., Kim, H.-S., Ferreira Coelho, L. G., et al. (2019). A genome-scale metabolic model of soybean (Glycine max) highlights metabolic fluxes in seedlings. Plant Physiol. 180, 1912-1929. doi: 10.1104/pp.19.00122

Muñoz, N., Liu, A., Kan, L., Li, M. W., and Lam, H. M. (2017). Potential uses of wild germplasms of grain legumes for crop improvement. Int. J. Mol. Sci. 18:328. doi: 10.3390/ijms 18020328

Muñoz, N., Qi, X., Li, M.-W., Xie, M., Gao, Y., Cheung, M.-Y., et al. (2016). Improvement in nitrogen fixation capacity could be part of the domestication process in soybean. Heredity 117, 84-93. doi: 10.1038/hdy.2016.27

Mutch, L. A., and Young, J. P. W. (2004). Diversity and specificity of Rhizobium leguminosarum biovar viciae on wild and cultivated legumes. Mol. Ecol. 13, 2435-2444. doi: 10.1111/j.1365-294X.2004.02259.x

Nouwen, N., Arrighi, J.-F., Cartieaux, F., Chaintreuil, C., Gully, D., Klopp, C., et al. (2017). The role of rhizobial (NifV) and plant (FEN1) homocitrate synthases in Aeschynomene/photosynthetic Bradyrhizobium symbiosis. Sci. Rep. 7:448. doi: 10.1038/s41598-017-00559-0

Orth, J. D., Thiele, I., and Palsson, B. Ø (2010). What is flux balance analysis? Nat. Biotechnol. 28, 245-248. doi: 10.1038/nbt.1614

Oruru, M. B., Njeru, E. M., Pasquet, R., and Runo, S. (2017). Response of a wild-type and modern cowpea cultivars to arbuscular mycorrhizal inoculation in sterilized and non-sterilized soil. J. Plant Nutr. 41, 90-101. doi: 10.1080/ 01904167.2017.1381728

Ott, T., Sullivan, J., James, E. K., Flemetakis, E., Günther, C., Gibon, Y., et al. (2009). Absence of symbiotic leghemoglobins alters bacteroid and plant cell differentiation during development of Lotus japonicus root nodules. Mol. Plant Microbe Interact. 22, 800-808. doi: 10.1094/mpmi-22-7-0800

Ott, T., van Dongen, J. T., Günther, C., Krusell, L., Desbrosses, G., Vigeolas, H., et al. (2005). Symbiotic leghemoglobins are crucialfor nitrogen fixation in legume root nodules but not for general plant growth and development. Curr. Biol. 15, 531-535. doi: 10.1016/j.cub.2005.01.042

Pérez-jaramillo, J. E., Carrión, V. J., Bosse, M., Ferrão, L. F. V., de Hollander, M., Garcia, A. A. F., et al. (2017). Linking rhizosphere microbiome composition of wild and domesticated Phaseolus vulgaris to genotypic and root phenotypic traits. ISME J. 11, 2244-2257. doi: 10.1038/ismej.2017.85

Pérez-Jaramillo, J. E., Mendes, R., and Raaijmakers, J. M. (2016). Impact of plant domestication on rhizosphere microbiome assembly and functions. Plant Mol. Biol. 90, 635-644. doi: 10.1007/s11103-015-0337-7
Pfau, T., Christian, N., Masakapalli, S. K., Swee, L. J., Poolman, M. G., and Ebenhöh, O. (2018). The intertwined metabolism during symbiotic nitrogen fixation elucidated by metabolic modelling. Sci. Rep. 8:12504. doi: 10.1038/ s41598-018-30884-x

Plett, J. M., Plett, K. L., Bithell, S. L., Mitchell, C., Moore, K., Powell, J. R., et al. (2016). Improved Phytophthora resistance in commercial chickpea (Cicer arietinum) varieties negatively impacts symbiotic gene signalling and symbiotic potential in some varieties. Plant Cell Environ. 39, 1858-1869. doi: 10.1111/pce. 12757

Prashar, P., and Vandenberg, A. (2017). Genotype-specific responses to the effects of commercial Trichoderma formulations in lentil (Lens culinaris ssp. culinaris) in the presence and absence of the oomycete pathogen Aphanomyces euteiches. Biocontrol Sci. Technol. 27, 1123-1144. doi: 10.1080/09583157.2017.137 6035

Prince, S. J., Song, L., Qiu, D., Maldonado dos Santos, J. V., Chai, C., Joshi, T., et al. (2015). Genetic variants in root architecture-related genes in a Glycine soja accession, a potential resource to improve cultivated soybean. BMC Genomics 16:132. doi: 10.1186/s12864-015-1334-6

Provorov, N. A., and Tikhonovich, I. A. (2003). Genetic resources for improving nitrogen fixation in legume-rhizobia symbiosis. Genet. Resour. Crop Evol. 50, 89-99. doi: 10.1023/A:1022957429160

Pueppke, S. G., and Broughton, W. J. (1999). Rhizobium sp. strain NGR234 and R. fredii USDA257 share exceptionally broad, nested host ranges. Mol. Plant Microbe Interact. 12, 293-318. doi: 10.1094/MPMI.1999.12.4.293

Rambla, J. L., López-Gresa, M. P., Bellés, J. M., and Granell, A. (2015). "Metabolomic profiling of plant tissues," in Plant Functional Genomics, eds J. Alonso and A. Stepanova (New York, NY: Humana Press).

Resendis-Antonio, O., Hernández, M., Mora, Y., and Encarnación, S. (2012). Functional modules, structural topology, and optimal activity in metabolic networks. PLoS Comput. Biol. 8:e1002720. doi: 10.1371/journal.pcbi.1002720

Resendis-Antonio, O., Reed, J. L., Encarnación, S., Collado-Vides, J., and Palsson, B. (2007). Metabolic reconstruction and modeling of nitrogen fixation in Rhizobium etli. PLoS Comput. Biol. 3:e192. doi: 10.1371/journal.pcbi.0030192

Roessner, U., Luedemann, A., Brust, D., Fiehn, O., Linke, T., Willmitzer, L., et al. (2001). Metabolic profiling allows comprehensive phenotyping of genetically or environmentally modified plant systems. Plant Cell 13, 11-29. doi: 10.2307/ 3871150

Rubio, L. M., and Ludden, P. W. (2008). Biosynthesis of the iron-molybdenum cofactor of nitrogenase. Annu. Rev. Microbiol. 62, 93-111. doi: 10.1146/ annurev.micro.62.081307.162737

Schultze, M., and Kondorosi, A. (1998). Regulation of symbiotic root nodule development. Annu. Rev. Genet. 32, 33-57. doi: 10.1146/annurev.genet.32.1.33

Singh, D. P., Singh, H. B., and Prabha, R. (2016). Microbial Inoculants in Sustainable Agricultural Productivity: Vol. 1: Research Perspectives. Delhi: Springer, doi: 10.1007/978-81-322-2647-5

Stacey, G. (2007). “The rhizobium-legume nitrogen-fixing symbiosis," in Biology of the Nitrogen Cycle, eds H. Bothe, S. J. Ferguson, and W. E. Newton (Amsterdam: Elsevier), doi: 10.1016/B978-044452857-5.50011-4

Sulieman, S., and Tran, L.-S. P. (2014). Symbiotic nitrogen fixation in legume nodules: metabolism and regulatory mechanisms. Int. J. Mol. Sci. 15, 1938919393. doi: 10.3390/ijms151119389

Szczałba, M., Kopta, T., Gąstol, M., and Sêkara, A. (2019). Comprehensive insight into arbuscular mycorrhizal fungi, Trichoderma spp. and plant multilevel interactions with emphasis on biostimulation of horticultural crops. J. Appl. Microbiol. 127, 630-647. doi: 10.1111/jam.14247

Tajini, F., Trabelsi, M., and Drevon, J. J. (2012). Combined inoculation with Glomus intraradices and Rhizobium tropici CIAT899 increases phosphorus use efficiency for symbiotic nitrogen fixation in common bean (Phaseolus vulgaris L.). Saudi J. Biol. Sci. 19. doi: 10.1016/j.sjbs.2011.11.003

Tang, F., Yang, S., Liu, J., and Zhu, H. (2016). Rj4, a gene controlling nodulation specificity in soybeans, encodes a Thaumatin-Like protein but not the one previously reported. Plant Physiol. 170, 26-32. doi: 10.1104/pp.15.01661

Terpolilli, J. J., Hood, G. A., and Poole, P. S. (2012). What determines the efficiency of N2-fixing rhizobium-legume symbioses? Adv. Microb. Physiol. 60, 325-389. doi: 10.1016/B978-0-12-398264-3.00005-X

Tian, L., Shi, S., Ma, L., Tran, L. P., and Tian, C. (2020). Community structures of the rhizomicrobiomes of cultivated and wild soybeans in their continuous cropping. Microbiol. Res. 232:126390. doi: 10.1016/j.micres.2019.126390 
Urnov, F. D., Rebar, E. J., Holmes, M. C., Zhang, H. S., and Gregory, P. D. (2010). Genome editing with engineered zinc finger nucleases. Nat. Rev. Genet. 11, 636-646. doi: 10.1038/nrg2842

Valdenegro, M., Barea, J. M., and Azcón, R. (2001). Influence of arbuscularmycorrhizal fungi, Rhizobium meliloti strains and PGPR inoculation on the growth of Medicago arborea used as model legume for re-vegetation and biological reactivation in a semi-arid mediterranean area. Plant Growth Regul. 34, 233-240. doi: 10.1023/A:1013323529603

Vauclare, P., Bligny, R., Gout, E., and Widmer, F. (2013). An overview of the metabolic differences between Bradyrhizobium japonicum 110 bacteria and differentiated bacteroids from soybean (Glycine max) root nodules: an in vitro $13 \mathrm{C}$ - and $31 \mathrm{P}$-nuclear magnetic resonance spectroscopy study. FEMS Microbiol. Lett. 343, 49-56. doi: 10.1111/1574-6968. 12124

Vázquez-Limón, C., Hoogewijs, D., Vinogradov, S. N., and Arredondo-Peter, R. (2012). The evolution of land plant hemoglobins. Plant Sci. 191-192, 71-81. doi: 10.1016/j.plantsci.2012.04.013

Wang, H., Man, C. X., Wang, E. T., and Chen, W. X. (2009). Diversity of rhizobia and interactions among the host legumes and rhizobial genotypes in an agricultural-forestry ecosystem. Plant Soil 314, 169-182. doi: 10.1007/s11104008-9716-z

Wang, L., Rubio, M. C., Xin, X., Zhang, B., Fan, Q., Wang, Q., et al. (2019). CRISPR/Cas 9 knockout of leghemoglobin genes in Lotus japonicus uncovers their synergistic roles in symbiotic nitrogen fixation. New Phytol. 224, 818-832. doi: $10.1111 / \mathrm{nph} .16077$

Wang, L., Wang, L., Tan, Q., Fan, Q., Zhu, H., Hong, Z., et al. (2016). Efficient inactivation of symbiotic nitrogen fixation related genes in Lotus japonicus using CRISPR-Cas9. Front. Plant Sci. 7:1333. doi: 10.3389/fpls.2016. 01333

Wang, L., Wang, L., Zhou, Y., and Duanmu, D. (2017). Use of CRISPR/Cas9 for symbiotic nitrogen fixation research in legumes. Prog. Mol. Biol. Transl. Sci. 149, 187-213. doi: 10.1016/bs.pmbts.2017.03.010

Wang, Q., Yang, S., Liu, J., Terecskei, K., Abrahám, E., Gombár, A., et al. (2017). Host-secreted antimicrobial peptide enforces symbiotic selectivity in Medicago truncatula. Proc. Natl. Acad. Sci. U.S.A. 114, 6854-6859.

Wang, X., Pan, Q., Chen, F., Yan, X., and Liao, H. (2011). Effects of co-inoculation with arbuscular mycorrhizal fungi and rhizobia on soybean growth as related to root architecture and availability of $\mathrm{N}$ and P. Mycorrhiza. 21, 173-181. doi: 10.1007/s00572-010-0319-1

Weese, D. J., Heath, K. D., Dentinger, B. T. M., and Lau, J. A. (2015). Long-term nitrogen addition causes the evolution of less-cooperative mutualists. Evolution 69, 631-642. doi: 10.1111/evo.12594
Woo, S. L., Ruocco, M., Vinale, F., Nigro, M., Marra, R., Lombardi, N., et al. (2014). Trichoderma-based products and their widespread use in agriculture. Open Mycol. J. 8. doi: 10.2174/1874437001408010071

Wu, L. J., Wang, H. Q., Wang, E. T., Chen, W. X., and Tian, C. F. (2011). Genetic diversity of nodulating and non-nodulating rhizobia associated with wild soybean (Glycine soja Sieb. \& Zucc.) in different ecoregions of China. FEMS Microbiol. Ecol. 76, 439-450. doi: 10.1111/j.1574-6941.2011.01064.x

Yang, S., Wang, Q., Fedorova, E., Liu, J., Qin, Q., Zheng, Q., et al. (2017). Microsymbiont discrimination mediated by a host-secreted peptide in Medicago truncatula. Proc. Natl. Acad. Sci. U.S.A. 114, 6848-6853.

Yang, Y., Hu, X. P., and Ma, B. G. (2017). Construction and simulation of the Bradyrhizobium diazoefficiens USDA110 metabolic network: a comparison between free-living and symbiotic states. Mol. Biosyst. 13, 607-620. doi: 10. 1039/C6MB00553E

Ye, H., Gemperline, E., Venkateshwaran, M., Chen, R., Delaux, P.-M., HowesPodoll, M., et al. (2013). MALDI mass spectrometry-assisted molecular imaging of metabolites during nitrogen fixation in the Medicago truncatula -Sinorhizobium meliloti symbiosis. Plant J. 75, 130-145. doi: 10.1111/tpj.12191

Zahran, H. H. (1999). Rhizobium-legume symbiosis and nitrogen fixation under severe conditions and in an arid climate. Microbiol. Mol. Biol. Rev. 63, 968-989. doi: 10.1128/mmbr.63.4.968-989.1999

Zhang, D., Song, H., Cheng, H., Hao, D., Wang, H., Kan, G., et al. (2014). The acid phosphatase-encoding gene GmACP1 contributes to soybean tolerance to low-phosphorus stress. PLoS Genet. 10:e1004061. doi: 10.1371/journal.pgen. 1004061

Zhang, J., Zhang, J., Zhang, P., He, P., Song, H., Zhang, J., et al. (2019). Rhizosphere fungal diversity of wild and cultivated soybeans in field and greenhouse experiments. Int. J. Agric. Biol. 21, 479-485. doi: 10.17957/IJAB/15.0918

Zhao, H., Li, M., Fang, K., Chen, W., and Wang, J. (2012). In silico insights into the symbiotic nitrogen fixation in Sinorhizobium meliloti via metabolic reconstruction. PLoS One 7:e31287. doi: 10.1371/journal.pone.0031287

Conflict of Interest: The authors declare that the research was conducted in the absence of any commercial or financial relationships that could be construed as a potential conflict of interest.

Copyright (c) $2020 \mathrm{Liu}, \mathrm{Ku}$, Contador and Lam. This is an open-access article distributed under the terms of the Creative Commons Attribution License (CC BY). The use, distribution or reproduction in other forums is permitted, provided the original author(s) and the copyright owner(s) are credited and that the original publication in this journal is cited, in accordance with accepted academic practice. No use, distribution or reproduction is permitted which does not comply with these terms. 